https://doi.org/10.3126/pragya.42029

\title{
Demographic Process of Population Ageing in Nepal
}

Kamala Bhandari*

\begin{abstract}
Population ageing is known as gradual increase in the proportion of the elderly population aged 60 years and above in the total population. In demographic process this study attempts to examine how demographic indicators i.e fertility and mortality explain the process of population ageing by subnational level in Nepal. In addition, the study also tries to assess the ageing parameters such as index of ageing, old age dependency ratio,and median age after 20 years to examine the speed of ageing process in population.This study follows descriptive and exploratory research design based on the existing data sheet of National Population Census, 2001 \& 2011 and also uses other previous censuses' data collected by CBS to explore the trends in these demographic indicators and parameters. Based on almost all these indicators, this study suggests that Nepal is already in the process of population ageing. Fertility and mortality are declining with increasing in life expectancy. The growth rate of the old aged population is higher than the national population growth rate by over three-fold. Similarly, almost all the parameters of ageing seem gradually increasing over the year, which makes the conformation that greater proportion of elderly individuals in the population. This trend seems in all over the sub regions of the country but in different manner. As compared with other pace in process of population ageing is higher in Hill region and, province 3. At last study conclude population ageing is driven with the transition of the fertility and mortalitywhere the level of fertility and mortality seems low with high life expectancy the proportion of aged population is higher and vice versa.
\end{abstract}

Key words: Population ageing, elderly population, demographic indicator

\section{Introduction}

In general, ageing is understood in two ways: individual ageing as the process of individuals growing older, or maturing 'progressive changes related to the passage of time. It is the multidimensional process of physical, psychological and social change. Population or demographic ageing as gradual increase in the proportion of the elderly population aged 60 years or older in the total population whiles the proportion of children and adolescent decrease. In demographic studies, increase in mean and median age of population is called

*Mrs. Bhandari is a Faculty Member of Population Studies, Patan Multiple Campus, TU, Nepal 
ageing of population. It is a natural outcome of demographic transition from high fertility and mortality to low fertility and mortality. (Shryock and Segal 1976).

Population ageing is in many ways a demographic success story, driven by changes in fertility and mortality that are associated with economic and social development. Progress in reducing child mortality, improving access to education and employment opportunities, advancing gender equality, and promoting reproductive health and access to family planning have all contributed to reductions in birth rates. Moreover, advancements in public health and medical technologies, along with improvements in living conditions, mean that people are living longer and, in many cases, healthier lives than ever before, particularly at advanced ages. Together, these declines in fertility and increases in longevity are producing substantial shifts in the population age structure, such that the share of children is shrinking while that share of older persons continues to grow (UNFPA, 2015).

Population ageing is global phenomenon. Worldwide population ageing has been considered one of the most important demographic phenomena that the older people are increasing almost all of the world. It is the dynamic process of demographic and socioeconomic transformation which reflects the increasing in the share of the elderly population aged 60 and over on the total population. It is considered as the natural process. When the fertility and mortality level continue to descend to much lower levels the life expectancy increases in the regions and the proportion of aged population also increases. Both the developed and developing countries of the world are experiencing the population ageing and there is growing concern about the population ageing in the world, (UNFPA, 2012).

Globally the proportion of older persons aged 60 years or over is growing at faster rate then the general population. In 2017, there are an estimated 962 million people aged 60 or over in the world, comprising 13 percent of the global population which is growing at a rate of about 3 percent per yearthat is almost three times that recorded for the total population $(1.1 \%)$. The growth is projected to accelerate in the coming decades. Currently, Europe has the greatest percentage of population aged 60 or over (25\%). Rapid ageing will occur in other parts of the world as well, so that by 2050 all regions of the world except Africa will have nearly a quarter or more of their populations at ages 60 and above. Compared to 2017, the number of persons aged 60 or above is expected to more than double by 2050 and more than triple by 2100, rising from 962 million in 2017 to 2.1 billion in 2050 and 3.1billion in 2100. For this age range, 65 percent of the global increase between 2017 and 2050 will occur in Asia, 14 percent in Africa, 11 percent in Latin America and the Caribbean, and the remaining 10 per cent in other areas (UNFPA, 2017).

Nepal is in the phase of age structure transition with a large proportin of young working age population. This present phase and the cosistent increment in the share of older age 
population over the year signifies that the elderly population will continue to increase in the years to come. Data show more than half of the population (56.9\%) falls in the 15-59 years category which conforms that the Nepali population is primarly young. The large proportion of youth also indicates that the population is gradually aging over the years. In a few decades the youth will shift into the catagory of 60 and above, there by increasing the proportion of the aged population.Thus the decreasing popuation of children and the increasing proportion of the working age and the older population affirms that Nepal is under going age structure transition and the population is gradually ageing (Limbu,2012).

The term "elderly population" and "old-aged population" are used interchangeably throughout this paper.

\section{Objectives of the Study}

The general objective of the study is to examine the demographic process of population ageing and its parameters in Nepal.

The specific objectives of the study are as follows:

a. To examine the demographic process of population ageing by sub-national level in Nepal

b. to examine how demographic indicators i.e fertility and mortality explain the process of population ageing in Nepal

c. To assess the parameters of population ageingby sub-regions in Nepal

\section{Significance of the Study}

The finding of this study plays a significant role to provide additional ideas and input about the demographic process of population ageing and its parameter for individual, researcher and students, social, legal and political activists or advocators. The research will be good reference and clues for the NGOs, INGOs, CBOs who are working for the enhancement of the elderly people as well as it will provide reference material for those who are interested about it. Furthermore, the finding of this study will be helpful to policy maker, planner of the Government of Nepal to evaluate, revise and implement the elderly related policies.

\section{Methodology}

The paper has adopted the descriptive and exploratory research method based on the existing data sheet of 2001 \&2011, National Population Census. The data from these sources are used to examine demographic process of population ageing using the indicators of fertility, mortality, proportion of aged population 60 and above, average annual growth rate of population and elderly population, and proportion of population below 15 years of age and to examine the ageing parameter such as median age after 20 years, index of 
ageing and old aged dependency ratioto assess the tempo of population ageing in the total population in respect to the new structured sub regions of the country. To explore the trend in these demographic indicators, and parameters of population ageing, study has used the various censuses' data published by the CBS. Furthermore, this paper is based on review of existing literature mainly books, journal, article and reports.

\section{Interpretation and Analysis of the Data}

\section{Process of Population Ageing in Nepal}

A population is classified as ageing when older people become a proportionately larger share of total population. Here the process of population ageing is interpreted as how the proportion of aged people (60 years and above) occur in large share in the total population and how demographic drivers i.e fertility and mortality explain the process of population ageing by sub-national level in Nepal?

\section{Demographic Process of Population Ageing in Nepal}

The Demographic outcomes of size structure and spatial distribution of population are determined by the demographic process of fertility, mortality and migration. This section discusses trends in various demographic process such as fertility (CBR and TFR), mortality (CDR and IMR), life expectancy, population growth rate with old aged growth to examine process of ageing in Nepal. Above these factors are the key drivers of population ageing globally.

Nepal has experienced lower birth rate and declining mortality rate with increasing life expectancy over the times. This results in growing numbers and proportions of older population with decreasing the proportion of child-aged population aged 0-14 years throughout the Nation. Same scenario presents the data of table 1 in Nepal during 1961 to 2011. The census of 2011 indicates the fertility has declining at faster rate over the last decade. The CBR is estimated to be around 22 per thousand population. Similarly, the total fertility rate of women throughout her lifetime is expected to be around 2.6 children against 4.1 in 2001 and 5.6 in 1991. As well, data reveals the level of mortality is declining over the years as indicated by CDR and IMR with increasing life expectancy at birth. In Nepal, life expectancy was 36 years in 1961; increased to 60 years in 2001 and 67 years for the census, 2011. Due to these reasons the proportion of children aged 0-14 has declined to 35 percent of total population in 2011 from 42.4 percent in 1991 with increased in the proportion of older population; it accounts 8.13 percent in 2011 that increased from 3.3 percent in 1981. 
Table 1: Trend in Demographic Process of PopulationAgeing in Nepal

\begin{tabular}{|c|c|c|c|c|c|c|c|c|c|c|c|}
\hline $\begin{array}{l}\text { Census } \\
\text { year }\end{array}$ & CBR & TFR & $\begin{array}{l}\text { Population } \\
<15\end{array}$ & CDR & IMR & \multicolumn{3}{|c|}{ Life expectancy } & \multirow{2}{*}{$\begin{array}{l}\text { Popula } \\
\text { tion } \\
60+ \\
\end{array}$} & \multicolumn{2}{|c|}{$\begin{array}{l}\text { Population } \\
\text { Growth Rate }\end{array}$} \\
\hline & & & & & & male & Female & Total & & pop & total \\
\hline 1961 & 47.0 & - & 39.9 & 22.0 & - & - & - & 36.27 & 5.3 & - & 1.65 \\
\hline 1971 & 42.0 & 6.3 & 40.5 & 21.4 & 172. & 42.0 & 40.0 & 41.08 & 5.6 & 2.56 & 2.07 \\
\hline 1981 & 39.7 & 6.3 & 41.4 & 13.5 & $\begin{array}{r}117 . \\
0\end{array}$ & 50.9 & 48.8 & 48.1 & 5.7 & 2.79 & 2.62 \\
\hline 1991 & 39.0 & 5.2 & 42.4 & 13.3 & 97.0 & 55.0 & 53.5 & 54.27 & 5.8 & 2.25 & 2.10 \\
\hline 2001 & 33.3 & 3.3 & 39.4 & 10.3 & 64.0 & 61.8 & 61.9 & 60.34 & 6.5 & 3.19 & 2.24 \\
\hline 2011 & 22.4 & 2.5 & 34.9 & 7.30 & 40.5 & 65.4 & 68.0 & 66.60 & 8.1 & 3.77 & 1.35 \\
\hline
\end{tabular}

Source:15\% Sample Data Sheet 2011 Census, Datasheet 1991, and 2001, \& CBS 2014

The demographic structure of a country can be understood by the analysis of its population growth rate. Data shows the average annual growth rate of the elderly population is always higher than that of the total population. During the years 2001-2011 the elderly population in Nepal is growing steadely at the rate of 3.77 percent per year which was three times higher then the annual population growth rate (1.35\%). It shows Nepal is already in the process of population ageing.

\section{Demographic Processof Population Ageing by Ecological Belt}

The demographic indicators, used to analyze the process of ageing in population shows, all three regions are already in the process of population ageing but in different manner. During the period 1981 -2011, all three regions have experienceddeclined in the level of fertility and mortality along with increasing in life expectancy (for both sexes) over the years. Due to these reasons, proportion of child population under age 15 is decreasing with increasing in the proportion of the elderlypopulation. As measured by these indicators, data 
reveal the pace of ageing process is higher in Hill with low level of fertility (TFR 2.43 and CBR20.5in 2011) mortality (CDR 7.75, IMR 30.7 declined from 164 per thousand live births in 1981) with higher life expectancies for both sexes, whereas the proportion of old aged population was observe higher in Mountain (8.80\%) due to the out migration of working age population from this area.

Table 2: Trend in Demographic Process of Population Ageing by Ecological Belt

\begin{tabular}{|c|c|c|c|c|c|c|c|c|c|c|}
\hline \multirow[t]{2}{*}{ Areas } & \multirow[t]{2}{*}{ CBR } & \multirow[t]{2}{*}{ TFR } & \multirow{2}{*}{$\begin{array}{l}\text { Population } \\
<15\end{array}$} & \multirow[t]{2}{*}{ CDR } & \multirow[t]{2}{*}{ IMR } & \multicolumn{2}{|c|}{ Life expectancy } & \multirow{2}{*}{$\begin{array}{l}\text { Population } \\
60+(\%)\end{array}$} & \multicolumn{2}{|c|}{ Population gr } \\
\hline & & & & & & Male & Female & & Pop 60+ & Total \\
\hline \multicolumn{11}{|c|}{ Mountain } \\
\hline 1981 & - & 5.9 & 38.9 & - & 187.0 & - & - & 6.2 & - & 1.35 \\
\hline 1991 & - & 6.6 & 41.4 & - & 155.0 & - & - & 5.8 & 1.0 & 1.02 \\
\hline 2001 & - & 4.39 & 40.8 & - & 112.2 & - & - & 7.2 & 1.8 & 1.57 \\
\hline 2011 & 24.55 & 3.76 & 38.2 & 8.51 & 50.2 & 62.8 & 65.5 & 8.8 & 3.8 & 0.54 \\
\hline \multicolumn{11}{|l|}{ Hill } \\
\hline 1981 & - & 6.2 & 40.8 & - & 164.0 & - & - & 6.1 & - & 1.65 \\
\hline 1991 & - & 5.8 & 42.4 & - & 83.0 & - & - & 6.2 & 1.9 & 1.61 \\
\hline 2001 & - & 3.21 & 38.9 & - & 66.2 & - & - & 7.0 & 2.9 & 1.97 \\
\hline 2011 & 20.54 & 2.43 & 33.5 & 7.75 & 30.7 & 67.6 & 70.3 & 8.6 & 3.3 & 1.06 \\
\hline \multicolumn{11}{|l|}{ Tarai } \\
\hline 1981 & - & 5.9 & 42.8 & - & 124.0 & - & - & 5.2 & - & 4.11 \\
\hline 1991 & - & 5.5 & 42.6 & - & 112.0 & - & - & 6.3 & 2.9 & 2.75 \\
\hline 2001 & - & 3.17 & 39.5 & - & 80.8 & - & - & 7.9 & 3.7 & 2.62 \\
\hline 2011 & 22.48 & 2.46 & 35.7 & 6.75 & 48.8 & 64.0 & 66.3 & 7.6 & 4.3 & 1.72 \\
\hline
\end{tabular}

Source:15\% Sample Data Sheet 2011, Datasheet 1991, and 2001, \& CBS 2014

Data also revel the average annual growth rate of older population is always greater then the growth rate of population, shows it was in increasing trend in all eco belts of the country. Among them, the speed of elderly population growth rate was observed highest inTarai, which is almost 4 times higher than total population growth rate. In Mountain, it was reported 3.8 percent as compared with 0.54 percent of total population growth rate and in 
Hill accounted 3.3 percent in 2011, which is also 3 times higher than the total population growth rate. All of these indicators showelderly population is growing faster in the country.

\section{Demographic Process of Population Ageing by Rural Urban Residence and Province level}

Table 3 clearly shows the wide variation in the demographic process and the proportion of aged and child population by rural urban residence and seven states of the country. As indicated by data, demographic process of population ageing is higher in urban area then the rural, which may be due to the better socio-economic development, better medical and health services, infrastructural development and better life style as compared to rural area. As well as the data also shows the higher proportion of elderly population lived in rural area as compared to urban.

Table3: Demographic Process of Population Ageing by Rural Urban Residence and Province level

\begin{tabular}{|c|c|c|c|c|c|c|c|c|c|c|}
\hline \multirow[t]{2}{*}{ Areas } & \multirow[t]{2}{*}{ CBR } & \multirow[t]{2}{*}{ TFR } & \multirow[t]{2}{*}{$\begin{array}{l}\text { Population }<1 \\
5 \text { years }\end{array}$} & \multirow[t]{2}{*}{ CDR } & \multirow[t]{2}{*}{ IMR } & \multicolumn{2}{|c|}{ Life Expectancy } & \multirow[t]{2}{*}{\begin{tabular}{|l|} 
Population \\
$60+(\%)$
\end{tabular}} & \multicolumn{2}{|c|}{$\begin{array}{l}\text { Population } \\
\text { growth rate }\end{array}$} \\
\hline & & & & & & Male & Female & & $\begin{array}{l}\text { Pop } \\
60+\end{array}$ & Total \\
\hline Urban & 18.8 & 1.8 & & 6.7 & 37.3 & 67.4 & 70.5 & 7.8 & - & \\
\hline Rural & 21.5 & 2.3 & & 7.0 & 43.2 & 65.1 & 66.2 & $8 . .8$ & - & \\
\hline Provience1 & 20.9 & 2.6 & 5.6 & 8.3 & 34.9 & 66.4 & 68.7 & 8.8 & 3.6 & 0.76 \\
\hline Provience2 & 25.1 & 2.8 & 7.9 & 5.6 & 56.6 & 62.8 & 64.9 & 8.5 & 3.7 & 1.60 \\
\hline Provience3 & 18.2 & 2.2 & 6.0 & 7.3 & 23.4 & 69.1 & 70.8 & 9.3 & 3.9 & 1.91 \\
\hline Provience4 & 18.5 & 2.1 & 2.9 & 8.2 & 23.3 & 69.4 & 70.9 & 7.8 & 2.7 & 0.37 \\
\hline Provience5 & 23.2 & 2.7 & 6.2 & 7.8 & 40.2 & 64.8 & 66.5 & 7.9 & 3.5 & 1.29 \\
\hline Provience6 & 28.2 & 4.6 & 2.5 & 8.2 & 52.3 & 60.9 & 62.9 & 3.3 & 7.8 & 1.80 \\
\hline Provience7 & 25.2 & 3.6 & 3.8 & 7.9 & 46.7 & 63.8 & 67.3 & 5.5 & 4.3 & 1.53 \\
\hline Nepal & 21.8 & 2.5 & 39.1 & 7.3 & 40.5 & 65.5 & 67.9 & 8.1 & 3.8 & 1.35 \\
\hline
\end{tabular}

Source: 15\% Sample Data Sheet 2011 Census \& Datasheet ,2001

Among the seven states of country, data shows state 3 recorded as the best in the demographic process of population ageing with low level of fertility and mortality along with high life expectancy which are stronger than the national level and the worst was observed in state 6 with high level of fertility and mortality along with low life expectancy, but the growth rate for elderly population was observed highest (7.8\%) as compared with 
others. It may be due to the gap between under reported in previous census and cover in recent ones. Due to the variation in these indicators among these states the proportion of aged population also ranges from 9.26 percent in state 3 and 3.31 percent in state 6 and the proportion of child population is observed largest in state 2 (7.86\%) and smallest in state 6 .

Data of the table 3 also show in all provinces the average annual growth rate of elderly population is greater than the total population growth rate. Highest elderly population growth rate is observed in province 6 that is almost 7 times higher than the total population growth rate followed by province 7 (4.3\%) and 3 (3.9\%), and lowest but higher then total population growth rate was observed in province $4(2.7 \%)$

\section{Parameters of Population Ageing}

Population ageing, which is driven by both declining fertility and increasing longevity, implies that successive cohorts can expect to live longer and have fewer adult children as potential sources of support in their old age. This section discusses trends in various descriptive measures of population ageing that are used often to examine the implications of shifting population age structures for intergenerational support systems. Above these factors are the key drivers of population ageing globally. To make the conformation about the population ageing i.e large share of elderly population in total population is measured by:

\section{Trend in the Parameters of Population Ageing in Nepal}

This section tries to examine the process of population ageing or the shifting in theage structures of the population in the country, various measures are used to describe such as index of ageing, age dependency ratio, elderly population growth rate, proportion of aged population, and median age after 20 years which are also known as the parameters of population ageing. Elderly population growth rate, and proportion of aged population have been already described in the process analysis but to show the correlation it with other parameter, here is also needed.

Table 4 shows the trends in various measures or the parameters of ageing in Nepal. Due to declining fertility and improving mortality over the years have contributed to decline in the dependency ratio in Nepal. Figure shows the total dependency ratio in 2011 was 76 percent steadily declined from 93 percent in 1981 in response to sustained reductions in fertility. Data also reveals that child dependency ratio was started to decreased from 2001, conversely elderly dependency ratio is increasing consistently over times, which accounted 9 percent in 1961, 11 percent in 1991 and reached 14 percent in 2011, due to increasing in the proportion of population ageing with decreasing child population in total population. 
In order to examine whether the population in Nepal is growing young or old, the index of ageing and median age has been computed. From table it is clear that both the index of ageing and median ageis increasing in Nepal over the yearswith increasing in the growth rate and proportion of elderly population. The population of Nepal is moving slowly from a young population to an old population. The increase in the index of aging from as well as the median age is noteworthy between the 1991 and 2001 censuses both increased from 13.8 to 16.7 and 19.9 to 22.3 since 1991 to 2011 respectively. It may be due to the improvement in living standard, health facilities and life expectancy and increase in the proportion of population at higher ages $(60+)$ with declining fertility and mortality. This scenario indicates the population of the country is growing towards ageing.

Table 4: Trends in the Parameters of Population Ageing in Nepal 1961-2011

\begin{tabular}{|c|c|c|c|c|c|c|}
\hline \multirow{2}{*}{$\begin{array}{l}\text { census } \\
\text { year }\end{array}$} & \multicolumn{2}{|c|}{ Dependency ratio } & & Index & Median & Proportion of \\
\hline & Child & old & Total & & & \\
\hline 1961 & 73.2 & 9.8 & 82.05 & 13.0 & 20.9 & 5.3 \\
\hline 1971 & 75.0 & 10.4 & 85.4 & 13.9 & 20.3 & 5.6 \\
\hline 1981 & 78.1 & 10.8 & 88.9 & 13.8 & 19.9 & 5.7 \\
\hline 1991 & 81.9 & 11.2 & 93.1 & 13.6 & 18.9 & 5.8 \\
\hline 2001 & 72.7 & 12.0 & 84.7 & 16.7 & 20.0 & 6.5 \\
\hline 2011 & 61.3 & 14.3 & 75.6 & 23.3 & 22.3 & 8.1 \\
\hline
\end{tabular}

Source: 15\% Sample Data Sheet 2011, Datasheet 1991, and 2001, \& CBS 2014

\section{Parameters of Population Ageing by Ecological Belt}

Variation in the parameters that areused to measure the population ageing, for ecological zones are presented in table 5. Figures indicates during the period 1971 to 1991 the ratio of overall dependency with child dependency was increased for all ecological belts, due to the high level of fertility. Then after 2001, the overall dependency ratio tends to decrease with decreasing in child dependency ratio and increasing old dependency ratio in all regions of the country, due mostly to the declining fertility and mortality with increasing life expectancy results reduction in the child population with increasing in the proportion of elderly population in the total population. 
Table 5: Trends in the Parameters of Population Ageing by Ecological Belt

\begin{tabular}{|c|c|c|c|c|c|c|}
\hline \multirow[t]{2}{*}{ Areas } & \multicolumn{3}{|c|}{ Dependency Ratio } & \multirow{2}{*}{$\begin{array}{l}\text { Index of } \\
\text { Ageing }\end{array}$} & \multirow{2}{*}{$\begin{array}{l}\text { Median } \\
\text { Age }\end{array}$} & \multirow{2}{*}{$\begin{array}{l}\text { Proportion of } \\
\text { population } 60+\end{array}$} \\
\hline & C.D. R & O. D. R & Total & & & \\
\hline \multicolumn{7}{|c|}{ Mountain } \\
\hline 1971 & 71.3 & 11.1 & 82.4 & 15.5 & - & - \\
\hline 1981 & 70.7 & 11.3 & 82.1 & 15.98 & - & 6.2 \\
\hline 1991 & 79.0 & 11.8 & 90.8 & 14.98 & & 5.8 \\
\hline 2001 & 76.3 & 13.6 & 89.8 & 17.8 & & 7.2 \\
\hline 2011 & 72.2 & 16.6 & 88.8 & 23.8 & 20 & 8.8 \\
\hline Hill & & & & & - & \\
\hline 1971 & 76.2 & 11.2 & 87.4 & 14.7 & - & - \\
\hline 1981 & 76.8 & 11.4 & 88.2 & 14.6 & - & 6.1 \\
\hline 1991 & 82.6 & 12.2 & 94.8 & 14.8 & & 6.2 \\
\hline 2001 & 71.6 & 12.9 & 84.6 & 18.1 & & 7.0 \\
\hline 2011 & 57.8 & 14.9 & 72.6 & 26.3 & 22 & 8.6 \\
\hline Terai & & & & & - & \\
\hline 1971 & 74.3 & 9.1 & 83.4 & 12.2 & - & - \\
\hline 1981 & 81.2 & 9.96 & 91.1 & 12.3 & - & 5.2 \\
\hline 1991 & 81.7 & 10.2 & 91.9 & 12.5 & & 6.3 \\
\hline 2001 & 73.2 & 10.95 & 84.1 & 14.95 & & 7.9 \\
\hline 2011 & 63.00 & 13.5 & 76.5 & 21.3 & 21 & 7.6 \\
\hline
\end{tabular}

Source: 15\% Sample Data Sheet 2011, Datasheet 1991, and 2001, \& CBS 2014

Note: O.D.R= Old Aged Dependency Ratio and C.D.R=Child Dependency Ratio

Data of the table also indicates the pattern of improvement in the index of ageing in Mountain, Hill, Tarai is almost same. All these parameters are increased steadily for each of eco belt over the times. At present highest index of ageing (26\%) and median age (22 years) was observed in hill region followed by mountain. In Tarairegions index of ageing and 
median age and old aged dependency was observed 21.3 percent, 21 years and (13.5) respectively in 2011 increased from the figure of 1971. As in the case of elderly population growth rate, all eco belts have experienced the trend of increasing over the times.

Hence, all of these parameters concluded the proportion of aging is increasing in the total population.

\section{Ageing Parameters byUrban Rural Residence and Province Level}

The variation in the parameters of population ageing, by seven province level and rural urban residence are presented in table 6 . Among of them, province 4 observed high old age dependency ratio and index of ageing and low valueof these parameters including median age, are found in province6 as compared with other provinces. The highest median age was observed in province 3 followed by province 1 and 4 . The highest old dependency ratio and index of ageing is mostly due to the high proportion of old aged population in total population.

Table 6: Situation of Parameters of Population Ageing for Rural Urban Residence and Provinces, 2011

\begin{tabular}{|l|c|c|c|l|l|l|}
\hline Areas & \multicolumn{2}{|l|}{ Dependency Ratio } & \multicolumn{2}{l|}{$\begin{array}{l}\text { Index of } \\
\text { ageing }\end{array}$} & Median Age & $\begin{array}{l}\text { Proportion of } \\
\text { population } \\
60+\end{array}$ \\
\hline & C.D. R & O.D. R & Total & & & \\
\hline Urban & 56.4 & 13.16 & 69.6 & 23.98 & 22.0 & 7.8 \\
\hline Rural & 70.4 & 16.4 & 86.8 & 24.8 & 20.0 & 8.8 \\
\hline & \multicolumn{7}{|l|}{} & & & \\
\hline Provience-1 & 56.2 & 14.2 & 71.1 & 26.6 & 23.0 & 8.8 \\
\hline Provience-2 & 71.5 & 13.9 & 5.4 & 19.6 & 20.0 & 8.5 \\
\hline Provience-3 & 45.9 & 13.1 & 59.0 & 29.6 & 24.0 & 9.3 \\
\hline Provience-4 & 57.1 & 18.7 & 75.8 & 35.5 & 23.0 & 7.8 \\
\hline Provience-5 & 65.0 & 14.2 & 79.2 & 22.4 & 20.0 & 7.9 \\
\hline Provience-6 & 79.6 & 11.8 & 91.4 & 14.7 & 18.0 & 3.3 \\
\hline Provience-7 & 74.7 & 14.3 & 88.9 & 18.98 & 19.0 & 5.5 \\
\hline Nepal & 61.3 & 14.3 & 75.6 & 24.4 & 22.0 & 8.1 \\
\hline
\end{tabular}

Source: 15\% Sample Data Sheet 2011, Datasheet 1991, and 2001, CBS 2014 
Between rural and urban residences, except median age, all other parameters are found high in rural area. As shown in the table except province 6 and 7, all other remaining states shows the values of parameters of ageing, is near with the national level. It shows the proportion of the elderly population is significant all over the country and shows Nepal is already in the phase of age shifting. Population of country is growing gradually towards Ageing.

Hence all of these above demographic indicators show Nepal is gradually moving towards population ageing and fertility and mortality are the key drivers of population ageing process. Population ageing or age transition is driven with the transition of fertility and mortality.

\section{Conclusion}

The study is about to examine the demographic process of population ageing and its parameters in Nepal with reference to the new structured sub regions of the country based on existing datasheet of 2001\& 2011 national population census and other population census data published by Central Bureau of Statistics in Nepal.

The demographic process of ageing was examined by taking indicators of fertility, mortality, population growth rate, old aged population growth rate, proportion of children under age 15 and proportion of old aged population, where as median age, index of ageing and age-dependency ratio are used as the parameters to examine the speed or pace of population ageing. Based on these almost all indicators and parameters, the study shows Nepal is already in the process of ageing.

Study found, Nepal has experienced declining birth rate, and declining mortality rate with increasing life expectancy. For eg. CBR is estimated to be around 22 per thousand decreased from 47 in 1971, and the TFR of women throughout her lifetime is expected to be around 2.25 children against 6.3 in 1971. As well level of mortality that is CDR and IMR declining with increasing life expectancy at birth over the years from 31 years in 1961 to 66 years in 2011. This resulted in noticeable changes in the age structure of the population in the country. Such that the share of children is shrinking $42 \%$ in 1991 to 31 in 2011) with growing numbers and proportions of older population aged 60 and above throughout the nation. It constitutes 8.1 percent of the total population, increased from 6.5 percent in 2001 with average annual growth rate of 3.7 percent, three times higher than national population growth rate $(1.35 \%)$. This trend seems in all over the sub regions of the country but in different manner.

Data shows pace of ageing process is higher in Hill with low level of fertility and mortality with higher median age and life expectancy, but the proportion of old aged population 
isobserved higher in Mountain (8.80\%) due to the out migration of working age population from this area. Among seven provinces, province 3 reported fastest in the pace of population ageing process with higher percentage of ageing (9.26\%).

Similarly, other indicators of ageing like old age dependency ratio, index of ageing and median age of population are gradually increasing over the year, which makes the conformation that greater proportion of elderly individuals in the population. For example, during the period 1971 to 2011, old age dependency has increased from 10.4 percent to 14.3 percent, index of ageing from 13.9 to 23.3 percent, median age from 20.3 to 22.3 years. These types of scenario areobserved in all sub regions of the country, due mostly to the result of a greater proportion of elderly individuals in the population of the country.

Hence, from the above explanation, the study concludes the fertility and mortality are the major drivers and the predictors of population ageing process. Population ageing or age transition is driven with the transition of fertility and mortality.

\section{References}

Central Bureau of Statistics (CBS). (1981). Population monograph of Nepal Volume I. Kathmandu:

National planning Commission Secretariat, Central Bureau of Statistics, Government of Nepal, Nepal.

Central Bureau of Statistics (CBS). (1991). Population monograph of Nepal. Volume I. Kathmandu:

National Planning Commission Secretariat, Central Bureau of Statistics, Government of Nepal, Nepal.

Central Bureau of Statistics (CBS). (2003). Population monograph of Nepal. Volume I. Kathmandu:

National Planning Commission Secretariat, Central Bureau of Statistics, Government of Nepal, Nepal.

Central Bureau of Statistics (CBS). (2014). Population monograph of Nepal. Volume I. Kathmandu:

National Planning Commission Secretariat, Central Bureau of Statistics, Government of Nepal, Nepal.

Shryok, H. S., Siegel, J. S \& Associates (1976). The methods and materials of demography. New York: Academic Press, Inc. United States.

Limbu, A. (2012). Age structure transition and senior citizens in Nepal: The impending challenges. Alliance for Social Dialogue, Policy Research Fellowship, Program 2012.

United Nation Fund for Population Association and Help Age International. (2012). Ageing in the

Twenty-First Century: A Celebration and A Challenge. UNFPA and Help Age International

United Nation (UN). (2015). World Population Ageing, Report. 2015. New York: Department of

Economic and Social Affairs Population Division, United State

United Nation (UN). (2017). World population prospectus, revision, 2017. New York: Department of Economomic and Social Affairs Population Devision, United States. 